The following resources related to this article are available online at www.sciencemag.org (this information is current as of November 13, 2009 ):

Updated information and services, including high-resolution figures, can be found in the online version of this article at:

http://www.sciencemag.org/cgi/content/full/326/5951/422

Supporting Online Material can be found at:

http://www.sciencemag.org/cgi/content/full/326/5951/422/DC1

A list of selected additional articles on the Science Web sites related to this article can be found at:

http://www.sciencemag.org/cgi/content/full/326/5951/422\#related-content

This article cites $\mathbf{2 8}$ articles, 12 of which can be accessed for free:

http://www.sciencemag.org/cgi/content/full/326/5951/422\#otherarticles

This article has been cited by 1 articles hosted by HighWire Press; see:

http://www.sciencemag.org/cgi/content/full/326/5951/422\#otherarticles

This article appears in the following subject collections:

Geochemistry, Geophysics

http://www.sciencemag.org/cgi/collection/geochem_phys

Microbiology

http://www.sciencemag.org/cgi/collection/microbio

Information about obtaining reprints of this article or about obtaining permission to reproduce this article in whole or in part can be found at:

http://www.sciencemag.org/about/permissions.dtl 
10. S. Hutt, D. Naish, D. M. Martill, M. J. Barker, P. Newbery, Cretac. Res. 22, 227 (2001)

11. R. B. J. Benson, J. Vert. Paleontol. 28, 732 (2008)

12. O. W. M. Rauhut, Palaeontol. 46, 903 (2003).

13. 0. W. M. Rauhut, A. Milner, J. Vert. Paleontol. 28, 130A (2008).

14. E. Stokstad, Science 306, 211 (2004).

15. Etymology: raptor, plunderer (Greek); rex, king (Greek); kriegsteini, after Roman Kriegstein, in whose honor the specimen was secured for scientific study. Holotype: LH PV18, partially articulated skeleton composed of disarticulated cranial bones representing most of the skull and postcranial skeleton, lacking portions of the forelimb and the distal one-half of the tail (beyond the 11th caudal). The holotype represents a young adult, as shown by fusion of the nasals and braincase elements in the skull and at least partial fusion of all neurocentral sutures. Cataloged in the collection of the Long Hao Institute of Geology and Paleontology (Hohhot, Nei Mongol Autonomous Region) and the University of Chicago (Chicago). Locality: Approximately $41^{\circ} 20^{\prime} \mathrm{N}$ and $119^{\circ} 40^{\prime} \mathrm{E}$, collected privately in the border area between Liaoning Province and the Nei Mongol Autonomous Region of the People's Republic of China. Horizon and associations: Lujiatun Beds of the Yixian Formation, comprising a tuffaceous fluvial facies of the Jehol Group with its well-known Jehol Biota that includes the teleost Lycoptera and pelecypods, which were found in association with the holotypic skeleton (16). The matrix around the fossil is light green, massive, poorly sorted, tuffaceous, micaceous sandstone with fibrous gypsum.
The light-colored, uncrushed bones were buried for the most part in articulation. The absence of laminated, fine-grained sediment or conchostracans characterizes the Lujiatun Beds of the Yixian Formation, dated to the late Early Cretaceous (Barremian-Aptian, 125 Ma) (16). Diagnosis: Basal tyrannosauroid with a narrow accessory pneumatic fossa within the antorbital fossa dorsal to the maxillary fenestra, jugal suborbital ramus of particularly narrow depth (transverse width approximately $60 \%$ of vertical depth), and absence of a vertical crest on the iliac blade dorsal to the acetabulum.

16. See supporting material on Science Online.

17. E. J. Rayfield, Zool. J. Linn. Soc. 144, 309 (2005)

18. E. Snively, D. M. Henderson, D. S. Phillips, Acta Palaeontol. Pol. 51, 435 (2006)

19. J. H. Hurum, P. J. Currie, Acta Palaeontol. Pol. 48, 161 (2003).

20. T. D. Carr, J. Vert. Paleontol. 19, 497 (1999).

21. J. A. Hopson, in Biology of the Reptilia, C. Gans, Ed. (Academic Press, London, 1979), vol. 9, pp. 39-146.

22. J. W. Franzosa, thesis, University of Texas at Austin (2004).

23. D. K. Zelenitsky, F. Therrien, Y. Kobayashi, Proc. R. Soc. London Ser. B 276, 667 (2009).

24. H. C. E. Larsson, P. C. Sereno, ]. A. Wilson, J. Vert. Paleontol. 20, 615 (2000).

25. F. Seebacher, J. Vert. Paleontol. 21, 51 (2001).

26. F. Therrien, D. M. Henderson, J. Vert. Paleontol. 27, 108 (2007).

27. K. M. Middleton, S. M. Gatesy, Zool. ]. Linn. Soc. 128 149 (2000)
28. A. G. Smith, D. G. Smith, B. M. Funnell, Atlas of Mesozoic and Cenozoic Coastlines (Cambridge Univ. Press, Cambridge, 1994), pp. 1-38.

29. P. C. Sereno, S. McAllister, S. L. Brusatte, PhyloInformatics 8, 1 (2005).

30. W. D. Matthew, B. Brown, Am. Mus. Novit. 89, 1 (1923).

31. For final drafts of all figures, we thank C. Abraczinskas. For preparation of fossil material, we thank personnel of the Western Paleontological Laboratories and the Fossil Lab at the University of Chicago. For assistance with computed tomography imaging, we thank C. Straus and C. Wietholt; for preparation of paleohistologic sections, we thank E. Lamm and D. Varricchio. For examination of fossil material in their care, we thank X. Xu, M. Norell, and $S$. Hutt. Supported by the Whitten-Newman Foundation and the National Geographic Society (to P.C.S.). This is Publication 3 of the Chinese-American Dinosaur Expeditions.

\section{Supporting Online Material}

www.sciencemag.org/cgi/content/full/1177428/DC1

Materials and Methods

Figs. $\mathrm{S} 1$ to $\mathrm{S} 8$

Tables S1 and S2

References

8 June 2009; accepted 25 August 2009

Published online 17 September 2009;

10.1126/science. 1177428

Include this information when citing this paper.

\title{
Deep-Sea Archaea Fix and Share Nitrogen in Methane-Consuming Microbial Consortia
}

\author{
Anne E. Dekas, ${ }^{*}$ Rachel S. Poretsky, Victoria J. Orphan*
}

Nitrogen-fixing (diazotrophic) microorganisms regulate productivity in diverse ecosystems; however, the identities of diazotrophs are unknown in many oceanic environments. Using single-cell-resolution nanometer secondary ion mass spectrometry images of ${ }^{15} \mathrm{~N}$ incorporation, we showed that deep-sea anaerobic methane-oxidizing archaea fix $\mathrm{N}_{2}$, as well as structurally similar $\mathrm{CN}^{-}$, and share the products with sulfate-reducing bacterial symbionts. These archaeal/bacterial consortia are already recognized as the major sink of methane in benthic ecosystems, and we now identify them as a source of bioavailable nitrogen as well. The archaea maintain their methane oxidation rates while fixing $\mathrm{N}_{2}$ but reduce their growth, probably in compensation for the energetic burden of diazotrophy. This finding extends the demonstrated lower limits of respiratory energy capable of fueling $\mathrm{N}_{2}$ fixation and reveals a link between the global carbon, nitrogen, and sulfur cycles.

$\mathrm{N}$ itrogen-fixing (diazotrophic) bacteria and archaea convert dinitrogen $\left(\mathrm{N}_{2}\right)$ into ammonia $\left(\mathrm{NH}_{3}\right)$ for assimilation. Biological $\mathrm{N}_{2}$ fixation counteracts the removal of bioavailable $\mathrm{N}$ by microbial processes such as denitrification and anaerobic ammonium oxidation (anammox) and provides a source of $\mathrm{N}$ to the majority of the biosphere that cannot directly assimilate $\mathrm{N}_{2}$. Many photosynthetic cyanobacteria fix $\mathrm{N}_{2}$ in ocean surface waters and have been the primary focus of studies on marine

Division of Geological and Planetary Sciences, California Institute of Technology, Pasadena, CA 91125, USA.

*To whom correspondence should be addressed. E-mail: vorphan@gps.caltech.edu (V.J.0.); dekas@gps.caltech.edu (A.E.D.) diazotrophy. Recently, a discrepancy between the calculated rates of oceanic denitrification and $\mathrm{N}_{2}$ fixation has suggested that other less well-studied or currently unknown diazotrophic microorganisms may exist and fix substantial amounts of $\mathrm{N}_{2}$ (1-5). Indeed, recent discoveries of new phylogenetically and physiologically diverse diazotrophs, including hyperthermophilic methanogens from hydrothermal vents (O), have shown that $\mathrm{N}_{2}$ fixation can occur in extreme environments and localized habitats of enhanced productivity in the deep sea $(5,7,8)$.

Here we show that syntrophic aggregates of archaea (of the ANME-2 group) and bacteria [Desulfosarcina/Desulfococcus (DSS)] mediating sulfate-dependent anaerobic oxidation of methane $\left(\mathrm{CH}_{4}\right)(\mathrm{AOM})$ in deep-sea sediments are capable of $\mathrm{N}_{2}$ fixation. The ANME-2/DSS consortia have been studied in recent years both because of their potentially critical role in marine carbon cycling and their enigmatic obligate syntrophy $(9,10)$. These consortia are most abundant in areas of high $\mathrm{CH}_{4}$ concentration, such as cold seeps, but are present throughout continental margin sediments [( 9$)$ and references therein]. They currently represent the main filter for oceanic $\mathrm{CH}_{4}$ release to the atmosphere, consuming up to $80 \%$ of naturally released $\mathrm{CH}_{4}$ in marine sediments (9); however, the specific mechanism(s) coupling the ANME-2 and DSS cells remains unclear. Recent metagenomic sequencing of the ANME-2/DSS consortia identified the presence of nitrogenase genes required for $\mathrm{N}_{2}$ fixation (nif genes) (11). This result, along with preliminary $\mathrm{N}$ isotope data, suggests that microbes within the consortia are able to fix $\mathrm{N}(11)$. We used submicronscale ion imaging by nanometer secondary ion mass spectrometry (nanoSIMS) coupled to fluorescence in situ hybridization (FISH) to specifically identify the ANME-2 species as diazotrophs while detailing and quantifying patterns of $\mathrm{N}$ assimilation within the individual members of these metabolically interdependent consortia.

Sediment samples from an active $\mathrm{CH}_{4}$ seep in the Eel River Basin, California, USA, were collected and anaerobically incubated with $\mathrm{CH}_{4}$ and one of several ${ }^{15} \mathrm{~N}$-labeled $\mathrm{N}$ sources (12) (table S1). Nitrogen fixation, as demonstrated by the assimilation of ${ }^{15} \mathrm{~N}$ from ${ }^{15} \mathrm{~N}_{2}$ in coaggregated ANME-2 and DSS cells, occurred in all AOM consortia measured after 6 months of incubation with $\mathrm{CH}_{4}$ (12) (Fig. 1, A and B, and Fig. 2A). ${ }^{15} \mathrm{~N}$ enrichment within the consortia was as high as $10.5^{15} \mathrm{~N}$ atom \%, which is 26 times the highest value observed in unlabeled ANME-2/DSS 
Fig. 1. Magnitude and distribution of ${ }^{15} \mathrm{~N}$ incorporation in representative methanotrophic ANME2/DSS consortia from sediments incubated with $\mathrm{CH}_{4}$ and different ${ }^{15} \mathrm{~N}$-labeled $\mathrm{N}$ sources, as indicated. (A to E) FISH using probes targeting ANME-2 (Eel932) in red and Desulfobacteraceae (DSS658) in green. (I to V) Ion micrographs of ${ }^{12} \mathrm{C}^{15} \mathrm{~N} /{ }^{12} \mathrm{C}^{14} \mathrm{~N}$ ratios of the same microbial consortia imaged by FISH in (A) to $(\mathrm{E})$, demonstrating the location of ${ }^{15} \mathrm{~N}$ incorporation. The scale range varies between ion micrographs, with the minimum consistently set to natural abundance ${ }^{15} \mathrm{~N} /{ }^{14} \mathrm{~N}$.
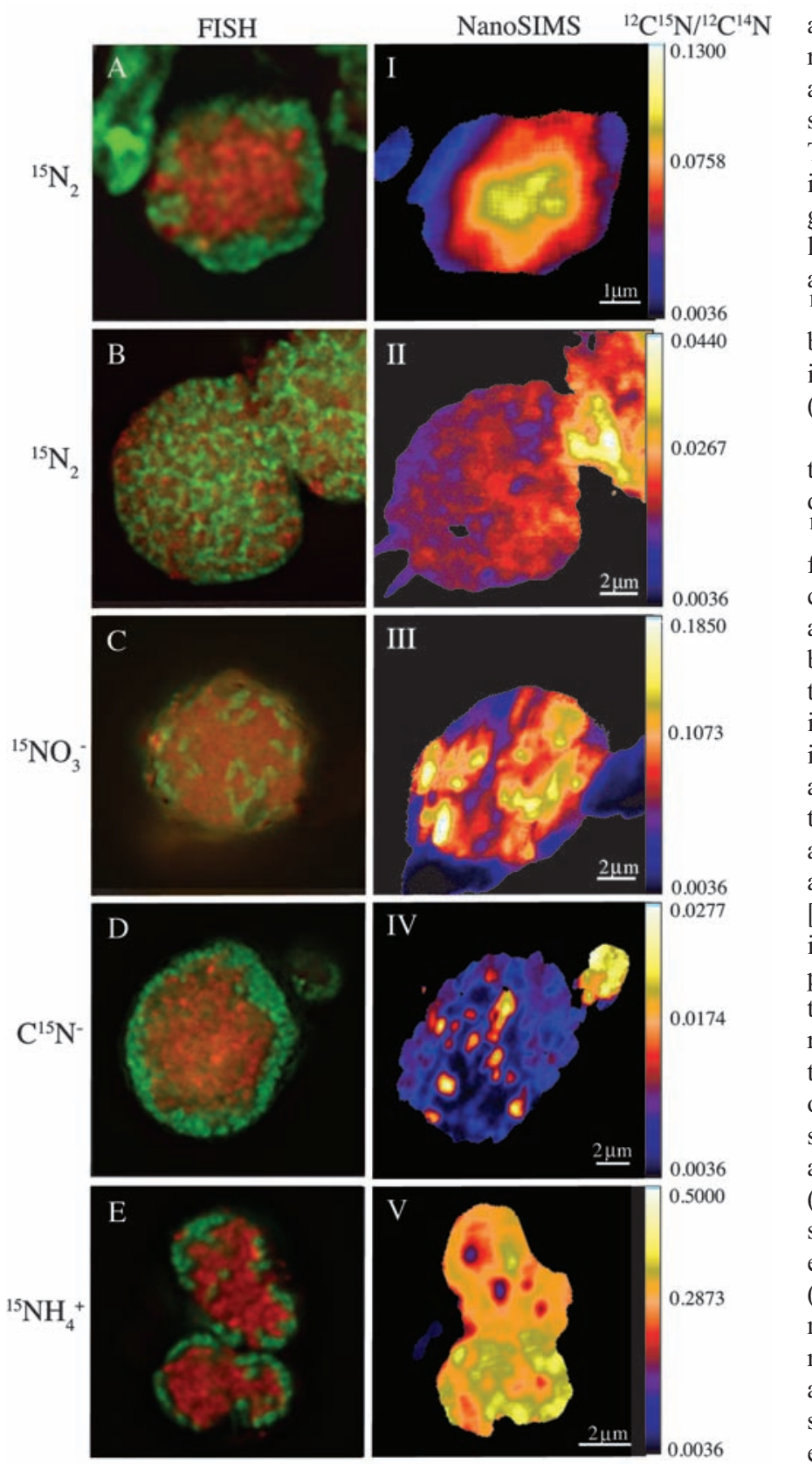

ally, ANME-2/DSS aggregates showed ${ }^{15} \mathrm{~N}$ enrichment colocalized with light $\delta^{13} \mathrm{C}$ biomass, a signal diagnostic of methanotrophic ANME-2 species $(11,17)(n=6$ aggregates; fig. S1). This differs from the variable pattern of ${ }^{15} \mathrm{~N}$ incorporation observed in the majority of aggregates from incubations amended with ${ }^{15} \mathrm{~N}$ labeled ammonium $\left({ }^{15} \mathrm{NH}_{4}{ }^{+}\right)$and nitrate $\left({ }^{15} \mathrm{NO}_{3}{ }^{-}\right)$ and indicates that the elevated enrichment from ${ }^{15} \mathrm{~N}_{2}$ within the ANME-2 archaea is attributable to diazotrophic activity, not simply a varying rate of protein synthesis between species (Fig. 1).

Serial FISH and SIMS images collected through individual aggregates reveal the threedimensional distribution of ${ }^{15} \mathrm{~N}$ assimilation from ${ }^{15} \mathrm{~N}_{2}$ within AOM consortia (Fig. 3). The difference in ${ }^{15} \mathrm{~N}$ atom $\%$ between the group of cells on the aggregate exterior (DSS-dominated) and the group in the interior (ANME-dominated) became greater with increasing penetration into the core of the aggregate, corresponding to an increasingly pure population of ANME in the interior (Fig. 3). Although the aggregate exterior averaged $31 \%$ less ${ }^{15} \mathrm{~N}$ enrichment than the interior, all of the DSS cells on the periphery of the aggregate were enriched in ${ }^{15} \mathrm{~N}$ relative to natural abundance \{average ${ }^{15} \mathrm{~N}$ atom $\%=3.47$ exterior $[n=313$ regions of interest (ROIs)] and 5.01\% interior ( $n=297$ ROIs), Fig. 3\}, suggesting a passage of reduced $\mathrm{N}$ from the ANME cells in the interior to the DSS-dominated exterior. The reduced ${ }^{15} \mathrm{~N}$ enrichment in the DSS cells relative to the ANME cells is consistent with the trend observed in ${ }^{15} \mathrm{~N}$ labeling studies of other symbioses, in which reduced $\mathrm{N}$ is shared between a diazotrophic and a nondiazotrophic partner $(18,19)$. Transfer of reduced $\mathrm{N}$ species between symbionts is common, often in exchange for energy-rich metabolites or structural protection (20). It is possible that inherent variations in metabolism and growth between the two partners may also lead to an offset in ${ }^{15} \mathrm{~N}$ enrichment (21), and the possibility of concurrent fixation by both syntrophic partners at differing rates cannot be excluded at this time. However, in the context of molecular data acquired in parallel, this scenario appears less likely.

The analysis of nif sequences recovered from the ${ }^{15} \mathrm{~N}_{2}$ sediment incubation was consistent with previous reports of a $\mathrm{CH}_{4}$ seep-specific nif $\mathrm{H}$ clade (fig. S2). The diverse nif $\mathrm{H}$ genes recovered clustered primarily within a divergent clade of sequences reported from geographically distant deep-sea $\mathrm{CH}_{4}$ seeps and whole-cell enrichments of ANME-2/DSS consortia from the Eel River Basin $(11,22)$ (fig. S2). The existence of this nif $\mathrm{H}$ clade highlights the strong similarities between putative diazotrophs at geographically distant $\mathrm{CH}_{4}$ seeps; however, its divergence from known diazotrophs has made previous attempts to assign the clade to either the Bacteria or Archaea specultative (22). We therefore collected and analyzed partial nif operons from the incubations and found that they contained the typical gene consortia (ranging from 0.35 to $0.4{ }^{15} \mathrm{~N}$ atom \%). lacking $\mathrm{CH}_{4}$ ) or sulfate reduction [incubations treated with the inhibitor sodium molybdate $\left(\mathrm{Na}_{2} \mathrm{MoO}_{4}\right)$ ] prevented ${ }^{15} \mathrm{~N}$ incorporation (Fig. 2 ), implying that $\mathrm{N}_{2}$ fixation requires a functioning symbiosis between the $\mathrm{CH}_{4}$-oxidizing ANME-2 and sulfate-reducing DSS partners. Other microbial cells from the ${ }^{15} \mathrm{~N}_{2}$ incubation were not enriched in ${ }^{15} \mathrm{~N}$ (maximum $0.38{ }^{15} \mathrm{~N}$ atom $\%, n=10$ cells), suggesting that ${ }^{15} \mathrm{~N}_{2}$ incorporation was specific to the ANME-2/DSS consortia over the incubation period and not due to nonspecific cycling of reduced ${ }^{15} \mathrm{~N}$ after fixation by an unrelated group of organisms. ${ }^{15} \mathrm{~N}$ was also incorporated from ${ }^{15} \mathrm{~N}$-labeled cyanide $\left(\mathrm{C}^{15} \mathrm{~N}^{-}\right)$, a toxic molecule structurally similar to
$\mathrm{N}_{2}$ and known to be detoxified and assimilated nitregenase is hypothesized to be a reli (s hypothesized to be a relict firom when the protein first evolved, than $\mathrm{N}_{2}$ fixation [such as cyanide detoxification (12, 14-16)].

$\mathrm{N}_{2}$ fixation appears to be primarily mediated by ANME-2, based on the distribution of ${ }^{15} \mathrm{~N}$ within the consortia. In aggregates of shelled morphology (an inner sphere of archaeal cells surrounded by an outer layer of bacterial cells, approximately 500 cells total; $n=5$ aggregates), the ${ }^{15} \mathrm{~N}$ label was concentrated in the center of the aggregate, where the ANME-2 biomass was concentrated (Figs. 1A and 3). Addition- 
Fig. 2. Effect of $\mathrm{N}$ source on rates of cellular growth and respiration. (A) ${ }^{15} \mathrm{~N}$ incorporation in ANME-2/DSS consortia from bulk sediment incubated with each of the indicated $\mathrm{N}$ sources and/or inhibitors. Each data point represents the average ${ }^{15} \mathrm{~N}$ (atom \%) value of the most ${ }^{15} \mathrm{~N}$-enriched ion image (depth plane) of a single aggregate. Symbol size and shape indicate the time the aggregate was incubated: small solid black circles, 1 month; small gray circles, 3 months; large gray circles, 4 months; large black circles, 6 months. The horizontal dashed line represents natural abundance ${ }^{15} \mathrm{~N} /{ }^{14} \mathrm{~N}$. NM, not measured. (Inset) Change in abundance of aggregates (aggs) over time in the $\mathrm{N}_{2}$ (dashed line) and $\mathrm{NH}_{4}{ }^{+}$(solid line) incubations determined by staining with $4^{\prime}, 6^{\prime}$-diamidino2-phenylindole. Error bars represent 1 SD from the mean. (B) Sulfide production in the different ${ }^{15} \mathrm{~N}$ sediment incubations. Each data point (square symbol) represents the value for a single incubation bottle at the time sampled, following the same symbol size and color trend noted in (A). There was no inhibition by 2 bromoethanesulfonic acid (BES) (12).

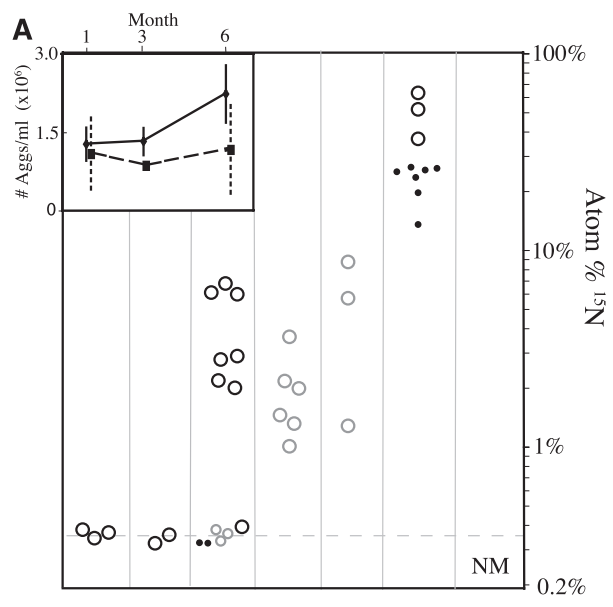

B

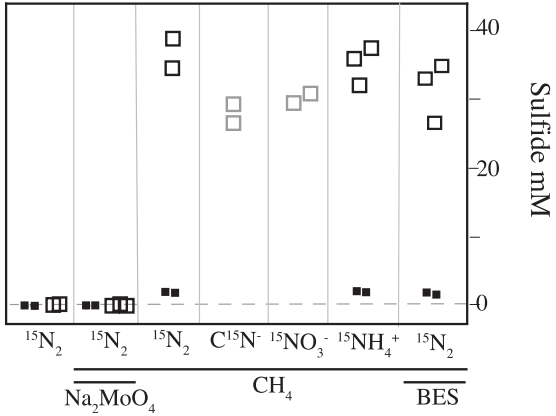

order (nif $\mathrm{H}$, nif $\mathrm{I} 1$, nif $\mathrm{I} 2$, nif $\mathrm{D}$, and nif $\mathrm{K}$ ) of the C-type operon in methanogenic archaea and some nonproteobacterial anaerobic diazotrophs (23) (fig. S3). Additionally, the nif D phylotypes within these operons grouped within a well-supported clade containing sequences retrieved from other $\mathrm{CH}_{4}$ seep sediment samples, methanogenic archaea (Methanococcus, 49\% similarity), and nonproteobacterial $\mathrm{N}$-fixing lineages rarely found at $\mathrm{CH}_{4}$ seeps but which have been hypothesized to have undergone lateral gene transfer with archaea (such as Clostridia and Roseiflexus spp.) $(23,24)$ (Fig. 4). In the context of seep microorganisms, these data are most consistent with an archaeal origin for these operons. The nif $\mathrm{H}$ fragments of the partial operons cluster within the putatively seep-specific nif $\mathrm{H}$ clade, suggesting that this clade is archaeal, and supporting our designation of the ANME-2 archaea as the primary diazotrophic microorganism in the consortia.

$\mathrm{N}_{2}$ fixation in ANME-2/DSS consortia is intriguing from an energetic standpoint; its cost is one of the highest for any anabolic process, requiring an investment of up to 16 adenosine triphosphate molecules (equivalent to $\sim 800 \mathrm{~kJ}$ ) for each $\mathrm{N}_{2}$ molecule reduced (8). Moreover, AOM coupled to sulfate reduction is thought to be one of the least energetically productive metabolisms known (10). At $\mathrm{CH}_{4}$ seeps, coupled $\mathrm{CH}_{4}$ oxidation and sulfate reduction reactions yield a total of approximately $40 \mathrm{~kJ} / \mathrm{mol}$ of $\mathrm{CH}_{4}$ (10) that must be shared between the two syn-
Fig. 3. Serial FISH and ${ }^{12} C^{15} N /{ }^{12} C^{14} N$ ion images in a representative shelled ANME-2/DSS aggregate showing the distribution of ${ }^{15} \mathrm{~N}$ incorporation from ${ }^{15} \mathrm{~N}_{2}$ with depth (left panels). In the FISH series, red indicates archaeal cells and green indicates bacteria. Comparison of ${ }^{15} \mathrm{~N}$ incorporation on the inside of the aggregate (dominated by archaea) and the outside (dominated by bacteria) is shown on the right. Each gray data point represents the ${ }^{15} \mathrm{~N} /{ }^{14} \mathrm{~N}$ of a hand-drawn ROI, approximating the size of a cell $(1 \mu \mathrm{m})(12)$. Box and whisker plots indicate $75 \%$, median, and $25 \%$ values for all ROls drawn in either the inside (ANME-2, red) or outside (DSS, green) at a particular depth in the aggregate. The inset at right shows an example of ROls designated for interior and exterior portions of the cell aggregate from a single depth. All ion micrograph values are scaled from 0.0036 to 0.11 .

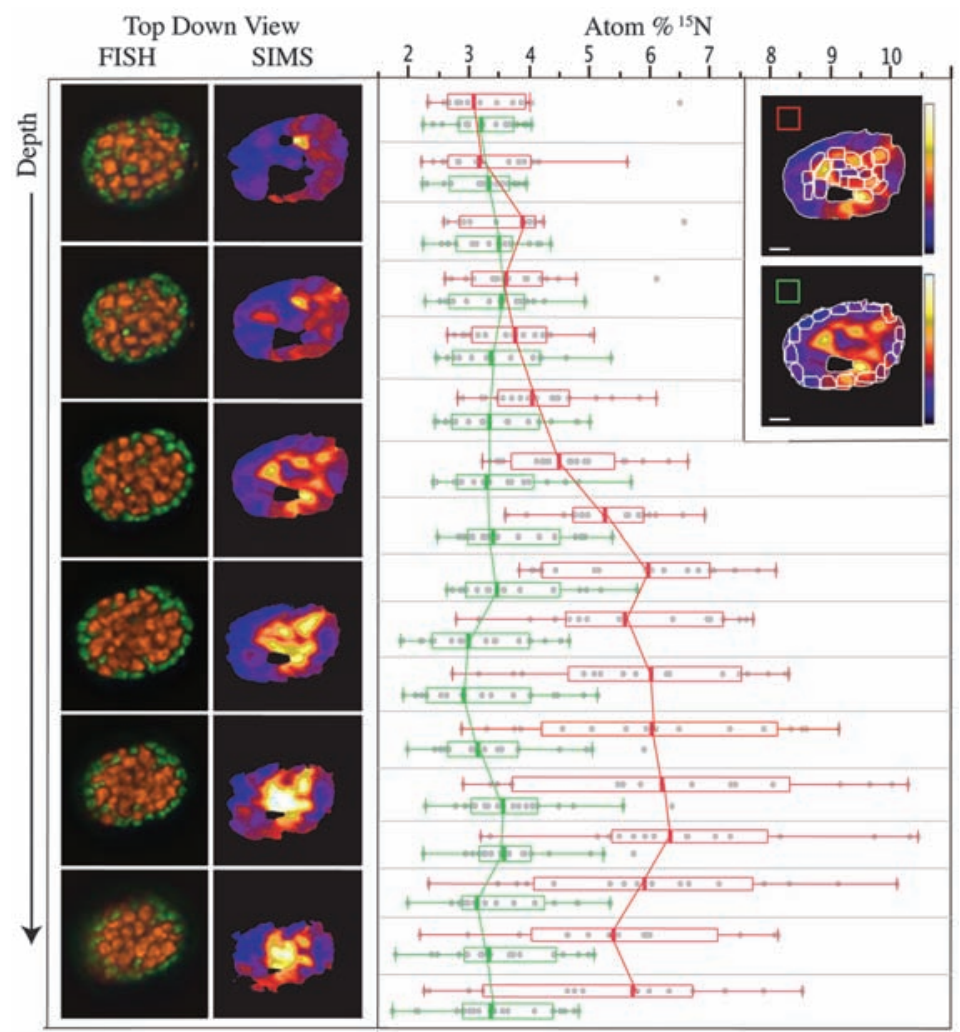


trophic partners. Although other energy-limited diazotrophic microorganisms exist (such as methanogens) none to our knowledge generate less energy per mole of substrate than the ANME2 species. One possibility is that in unusual environments, such as the deep sea, structural or mechanistic differences in the $\mathrm{N}_{2}$ fixation machinery may alter the energetic burden. The low sequence similarity of the recovered nif genes to those previously described suggests some deviation from characterized $\mathrm{N}_{2}$-fixing systems (Fig. 4 and figs. S2 and S3).

Slowed growth is a common response to the energetic burden of $\mathrm{N}_{2}$ fixation in active diazotrophs, including methanogenic archaea (25). Accordingly, using ${ }^{15} \mathrm{~N}$ incorporation as a proxy for growth, the ANME-2/DSS consortia in this study actively fixing $\mathrm{N}$ grew approximately 20 times slower on average than aggregates grown in parallel with ammonium (Fig. 2). Although ANME-2/DSS growth rates are substantially affected by the available $\mathrm{N}$ source, the rate of $\mathrm{AOM}$ by the consortia [estimated by $\mathrm{CH}_{4}$ dependent sulfide production (12)] was similar during growth on either $\mathrm{N}_{2}$ or $\mathrm{NH}_{4}$ (Fig. 2B). Therefore, regardless of the exact amount of energy required to fix $\mathrm{N}_{2}$ in these organisms, the consortia appear to compensate for the energetic burden of $\mathrm{N}_{2}$ fixation by slowing growth while maintaining similar rates of respiration.

The maintenance of nif genes by the ANME2 cells, and their consortial ability to fix $\mathrm{N}$ in the laboratory, imply that they do so in marine environments. Diazotrophy within deep-sea $\mathrm{CH}_{4}$ seeps has not been detected directly, but $\mathrm{N}_{2}$ fixation has been suggested at these locales, based on low $\delta^{15} \mathrm{~N}$ values of seep sediment and fauna $(26,27)$. Why $\mathrm{N}_{2}$ fixation would occur in anoxic marine sediments, often replete with ammonium, warrants further consideration. One explanation is that the $\mathrm{CH}_{4}$ seep environment differs from typical anoxic sediment in that the main source of $\mathrm{C}\left(\mathrm{CH}_{4}\right)$ is unaccompanied by $\mathrm{N}$, poising its consumers for $\mathrm{N}$ limitation, similar to photoautotrophs $(8)$ and aerobic methanotrophs (28). Indeed, measurements of pore water ammonium from the Eel River Basin $\mathrm{CH}_{4}$ seeps were highly variable, ranging from 101 to $16 \mu \mathrm{M}$ over a 6-cm sediment depth profile; these concentrations would not completely inhibit $\mathrm{N}_{2}$ fixation in cultured diazotrophic methanogens (such as Methanococcus maripaludis) (29). Even in ammonium-replete sediments, localized zones of $\mathrm{N}$ limitation may occur (for example, within

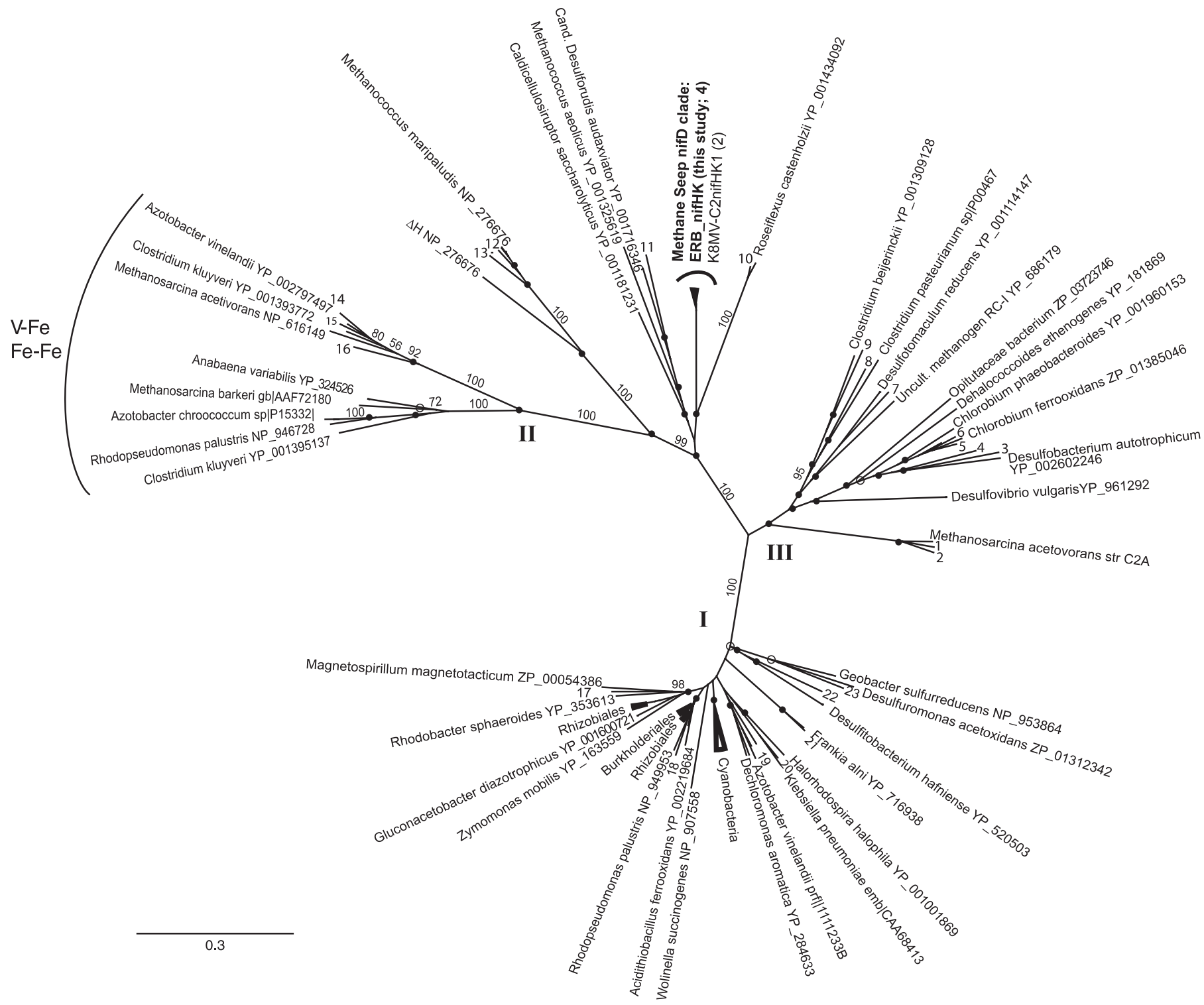

Fig. 4. Unrooted neighbor-joining tree of translated nifD sequences after global alignment. Bootstrap values from 85 to $100 \%$ (solid circles) and from 70 to $85 \%$ (open circles) are indicated at the nodes. The scale bar represents changes per amino acid position. The sequences obtained in this study are shown in bold. Alternative nitrogenases are those that use V-Fe and Fe-Fe cofactors ( $v n f \mathrm{D}$ and $a n f \mathrm{D}$, respectively). Roman numerals represent nitrogenase clusters as originally defined in (30). Names of sequences represented by numbers can be found in table S2. 
densely packed microbial consortia). Although the loss of nitrate and ammonium from $\mathrm{CH}_{4}$ seep sediments by catabolic bacterial processes (such as denitrification or anammox) has not yet been determined, these sinks for fixed $\mathrm{N}$ may also promote enhanced diazotrophy by the in situ microbial assemblage (3). Additionally, the current discrepancy in the oceanic fixed $\mathrm{N}$ budget underscores the possibility of new sources of fixed $\mathrm{N}$ in nontraditional and potentially unexpected habitats $(1-3,7)$. The extent to which the ANME-2/DSS consortia contribute to the putatively missing fraction of global fixed $\mathrm{N}$ inputs is unknown, but their input is probably not the only missing term in the equation. $\mathrm{N}_{2}$ fixation in ANME-2, combined with the diversity of nif $\mathrm{H}$ genes recovered from marine sediments here and previously $(5,11,22)$, suggests that our inventory of marine diazotrophs is incomplete and that we are only beginning to understand the extent and importance of benthic marine $\mathrm{N}_{2}$ fixation.

\section{References and Notes}

1. L. A. Codispoti, Biogeosciences 4, 233 (2007).

2. C. Mahaffey, A. F. Michaels, D. G. Capone, Am. J. Sci. 305, 546 (2005)

3. C. Deutsch, J. L. Sarmiento, D. M. Sigman, N. Gruber, J. P. Dunne, Nature 445, 163 (2007)

4. R. W. Fulweiler, S. W. Nixon, B. A. Buckley, S. L. Granger Nature 448, 180 (2007).
5. J. P. Zehr, B. D. Jenkins, S. M. Short, G. F. Steward, Environ. Microbiol. 5, 539 (2003).

6. M. P. Mehta, J. A. Baross, Science 314, 1783 (2006)

7. M. C. Horner-Devine, A. C. Martiny, Science 320, 757 (2008).

8. D. Karl et al., Biogeochemistry 57-58, 47 (2002).

9. W. S. Reeburgh, Chem. Rev. 107, 486 (2007).

10. M. Strous, M. S. M. Jetten, Annu. Rev. Microbiol. 58, 99 (2004).

11. A. Pernthaler et al., Proc. Natl. Acad. Sci. U.S.A. 105, 7052 (2008).

12. Information on materials and methods is available on Science Online.

13. J. K. Liu, C. H. Liu, C. S. Lin, Proc. Natl. Sci. Counc. Repub. China B 21, 37 (1997).

14. W. S. Silver, ]. R. Postgate, J. Theor. Biol. 40, 1 (1973).

15. J. Raymond, Rev. Mineral. Geochem. 59, 211 (2005).

16. I. Berman-Frank, P. Lundgren, P. Falkowski, Res. Microbiol. 154, 157 (2003)

17. V. J. Orphan, C. H. House, K. U. Hinrichs, K. D. McKeegan, E. F. DeLong, Science 293, 484 (2001).

18. C. P. Lechene, Y. Luyten, G. McMahon, D. L. Distel, Science 317, 1563 (2007).

19. S. Behrens et al., Appl. Environ. Microbiol. 74, 3143 (2008).

20. M. K. Udvardi, D. A. Day, Annu. Rev. Plant Physiol. Plant Mol. Biol. 48, 493 (1997).

21. V. J. Orphan, K. A. Turk, A. M. Green, C. H. House, Environ. Microbiol. 11, 1777 (2009).

22. H. Dang, X. Luan, ]. Zhao, J. Li, Appl. Environ. Microbiol. 75, 2238 (2009).

23. J. P. W. Young, in Genomes and Genomics of NitrogenFixing Organisms, R. Palacios, W. E. Newton, Eds. (Springer, Netherlands, 2005), pp. 221-241.

24. J. A. Leigh, Curr. Issues Mol. Biol. 2, 125 (2000).

25. P. A. Murray, S. H. Zinder, Nature 312, 284 (1984)

26. S. B. Joye et al., Chem. Geol. 205, 219 (2004).
27. J. Brooks et al., Science 238, 1138 (1987)

28. D. H. Buckley, V. Huangyutitham, S. F. Hsu, T. A. Nelson, Soil Biol. Biochem. 40, 1272 (2008).

29. P. S. Kessler, C. Daniel, J. A. Leigh, J. Bacteriol. 183, 882 (2001).

30. Y.-T. Chien, A. Auerbuch, A. D. Brabban, S. H. Zinder, ]. Bacteriol. 182, 3247 (2000)

31. We thank C. House, A. Schmitt, K. McKeegan, Y. Guan, ]. Eiler, and L. Remusat for assistance with the ion microprobe data collection; S. Joye, M. Boyles, M. Walton, J. Howard, N. Dalleska, O. Mason, A. Green, P. Tavormina, S. Goffredi, C. Gammon, and the shipboard party and crew of the R/V Atlantis and DSSV Alvin for support in the field and laboratory; and J. Howard, W. Fischer, ]. Amend, C. Anderson, D. Fike, D. Sigman, V. Rich, ]. Bailey, D. Newman, ]. Grotzinger, T. Hoehler, ]. Delacruz, and three anonymous reviewers for helpful suggestions regarding this manuscript. Funding was provided by NSF (grant MCB-0348492), the Gordon and Betty Moore Foundation, and an NSF Graduate Research Fellowship (A.E.D.). The Caltech Center for Microanalysis and nanoSIMS 50L are funded by the Gordon and Betty Moore Foundation, and the University of California Los Angeles ion microprobe is partially supported by the NSF Instrumentation and Facilities Program.

\section{Supporting Online Material}

www.sciencemag.org/cgi/content/full/326/5951/422/DC1

Materials and Methods

SOM Text

Figs. S1 to S3

Tables S1 to S4

References

25 June 2009; accepted 31 August 2009

$10.1126 /$ science. 1178223

\section{Generation of Functional Ventricular Heart Muscle from Mouse Ventricular Progenitor Cells}

Ibrahim J. Domian, ${ }^{1,2 *}$ Murali Chiravuri, ${ }^{1 *}$ Peter van der Meer, ${ }^{1,3 *}$ Adam W. Feinberg, ${ }^{4}$ Xi Shi, ${ }^{1}$ Ying Shao, ${ }^{1}$ Sean M. Wu, ${ }^{1,2}$ Kevin Kit Parker, ${ }^{2,4,5}$ Kenneth R. Chien ${ }^{1,2,6} \dagger$

The mammalian heart is formed from distinct sets of first and second heart field (FHF and SHF, respectively) progenitors. Although multipotent progenitors have previously been shown to give rise to cardiomyocytes, smooth muscle, and endothelial cells, the mechanism governing the generation of large numbers of differentiated progeny remains poorly understood. We have employed a two-colored fluorescent reporter system to isolate FHF and SHF progenitors from developing mouse embryos and embryonic stem cells. Genome-wide profiling of coding and noncoding transcripts revealed distinct molecular signatures of these progenitor populations. We further identify a committed ventricular progenitor cell in the Islet 1 lineage that is capable of limited in vitro expansion, differentiation, and assembly into functional ventricular muscle tissue, representing a combination of tissue engineering and stem cell biology.

$\mathrm{T}$ he mammalian heart is composed of a diversified set of muscle and nonmuscle cells that arise from multipotent progenitors in the first and second heart field (FHF and SHF, respectively) $(1,2)$. Defining the precise progenitor identity and the pathways that lead to ventricular myogenesis is critical for understanding cardiogenesis and also for regenerative cardiovascular medicine.

Accordingly, we generated a transgenic mouse with the red fluorescent protein dsRed under the control of an Isl1-dependent enhancer of the
Mef2c gene whose expression is restricted to the SHF (3-5). We bred this mouse line with a transgenic mouse line in which enhanced green fluorescent protein (eGFP) is controlled by the cardiac-specific Nkx2.5 enhancer $(6,7)$. By fluorescence microscopy of double transgenic embryos on embryonic day 9.5 (E9.5), the entire primitive heart tube was eGFP + , but only the right ventricle (RV) and the outflow tract (OFT) were also dsRed + . Further, the pharyngeal mesoderm (PM), which contributes to the RV and OFT $(8,9)$, was dsRed+ but eGFP- (Fig. 1, A to C). To delineate the in vivo expression of the reporters, we performed immunohistochemistry on E9.5 embryos and found that dsRed+/eGFP+ cells $(\mathrm{R}+\mathrm{G}+)$ were restricted to the $\mathrm{RV}$ and $\mathrm{OFT}$, dsRed-/eGFP+ cells $(\mathrm{R}-\mathrm{G}+)$ to the left ventricle (LV) and inflow tract (IFT), and dsRed+/eGFPcells $(\mathrm{R}+\mathrm{G}-)$ to the PM (Fig. 1D).

Embryonic stem cell (ESC) lines make use of many of the in vivo developmental programs, providing an attractive model system for lineage commitment. Therefore, we generated multiple ESC lines that harbor both the Nkx2.5-eGFP and the SHF-dsRed reporters (fig. S1A). Fluorescence microscopy of chimeric embryos from these ESC lines revealed faithful recapitulation of marker expression (fig. S1, B and C). In vitro differentiation by embryoid body (EB) formation resulted in discrete populations of $\mathrm{R}+\mathrm{G}+, \mathrm{R}+\mathrm{G}-$, and $\mathrm{R}-\mathrm{G}+$ cells by $\mathrm{EB}$ day 6 (fig. S1D).

${ }^{1}$ Cardiovascular Research Center, Massachusetts General Hospital, Charles River Plaza, CPZN 3200, 185 Cambridge Street, Boston, MA 02114-2790, USA. ${ }^{2}$ Harvard Stem Cell Institute, Cambridge, MA 02138, USA. ${ }^{3}$ Department of Cardiology, University Medical Center Groningen, Hanzeplein 1, 9700 RB Groningen, Netherlands. ${ }^{4}$ Disease Biophysics Group, School of Engineering and Applied Sciences, Harvard University, Cambridge, MA 02138, USA. ${ }^{5}$ The Wyss Institue for Biologically Inspired Engineering, Harvard University, Boston, MA 02115 , USA. ${ }^{6}$ Department of Stem Cell and Regenerative Biology, Harvard University, Cambridge, MA 02138, USA.

*These authors contributed equally to this work. †To whom correspondence should be addressed. E-mail: krchien@partners.org 